\title{
Functional fixedness: problem solution as a function of observing responses'
}

\author{
Sam Glucksberg \\ PRINCETON UNIVERSITY
}

\begin{abstract}
Abstraet
When Ss solve functional fixedness problems do they formulate the solution and then look for the object needed, or does perception of the functionally fixed object itself trigger solution? Duncker's candle problem was administered in tactual form so that discrete observing responses (touching the functionally fixed object, a box filled with tacks) could be observed and counted by $\mathrm{E}$. Problem solution occurred upon contact with the functionally fixed object. The specific contact immediately preceding problem solution was usually adventitious.
\end{abstract}

\section{Problem}

Associationistic formulations of problem solving posit that problem solution occurs when a cue and a response from different behavioral chains are contiguous (Cofer, 1957; Kendler et al., 1961; Kendler \& Kendler, 1962; Underwood, 1952). Consider Duncker's candle problems in these terms (Duncker, 1945). S, given a candle, matches and a box filled with thumbtacks, must use the box to mount the candle on a vertical screen. A cue, perception of the box, must occur contiguously with some other response, i. e., formulation of the problem (Cofer, 1957). This study was concerned with problem solution as a function of the cue properties of the box. According to the above analysis, problem solution need not occur upon initial perception of the box. However, problem solution, if it occurs at all, should occur at a time when the box can serve as a cue, that is, when it is being observed. By administering the candle problem in tactual form, observing responses can be observed and counted by $\mathrm{E}$. Two questions were asked: (1) Does problem solution occur at the time of initial contact with the box?; (2) If not, does problem solution occur at the time of some subsequent contact with the box?

\section{Method}

Ten male undergraduates enrolled in psychology courses at Princeton University served as Ss. At the beginning of each session $\mathrm{S}$ was seated at a table. On the table, concealed by a large box, were a candle, a small matchbox filled with thumbtacks, and three kitchen matches. To S's left was a cardboard screen, $24 \times 36$ in, mounted in a wooden frame. Each S was provided with fresh, unmarked materials. $S$ was told:

Look at the "wall." The problem is this. Under this cover are a candle and several common household objects. The problem is to affix the candle to the wall, this cardboard wall, using any of the objects on the table. You may not use this, . . or this (E pointed to sides and top of frame holding cardboard wall) to support the candle. The problem is considered solved when the candle is affixed to the wall and burns properly. As an incentive, a prize of $\$ 10.00$ will be awarded for the fastest solution. Now then, we are interested in how blind people function. Therefore, you will work on this problem blindfolded. (Opaque goggles were donned by S at this point.) When I say "begin," you may start.

The cover concealing the materials was removed and timing, using a Standard Electric Timer, was started when E said "begin:" Timing was stopped when $\mathrm{S}$ had pushed a tack through the box, placed the candle in or on the box, or had failed to use the box within $15 \mathrm{~min}$. A score of $15 \mathrm{~min}$. was assigned to failure Ss.

All manual contacts with the box were scored as observing responses. The observing responses were divided into two categories: exploratory and adventitious. When $S$ felt around for things on the table, contacts with the box were considered exploratory observing responses. When $\mathrm{S}$ touched the box while reaching for thumbtacks in the box, the observing responses were considered adventitious.

\section{Results and Diseussion}

Table 1 shows the mean solution times along with number of failures for the ten blindfolded Ss. Data from an earlier study (Glucksberg, 1962) with sighted Ss working under similar money incentives are included for purposes of comparison. Judging on the basis of solution time scores, the tactual form of the problem is only slightly more difficult than the visual Dm + (dominant response correct) form of the problem used earlier, in which the box was presented empty. The tactual Dmform used in the present study, in which the box was filled with tacks, is easier than the visual Dm- form. All Ss touched all the objects available, and all could give accurate reports of the particular objects available as well as the number of each object available. These data indicate that the tactual and visual forms of the problem are behaviorally comparable.

Table 1. Tactual and Visual Solution Time Scores

\begin{tabular}{|c|c|c|c|}
\hline Group & $\mathrm{N}$ & $\begin{array}{l}\text { Mean } \\
\text { (min.) }\end{array}$ & SD \\
\hline
\end{tabular}

$\begin{array}{llrrr}\text { Tactual (Dm-) } & 10 & 5.47 & 5.13 & 2 \\ \text { Visual }(\mathrm{Dm}-) & 32 & 11.08 & 4.84 & 16 \\ \text { Visual }(\mathrm{Dm}+) & 32 & 3.67 & 4.52 & 2\end{array}$


Table 2. Problem Solving Scores and Observing Behavior for Individual Subjects
S Solution Time

(min.)

0.60

0.85

1.06

2.38

3.76

3.99

5.00

7.02

$15.00+$

$15.00+$ (box contacts)

Exploratory Adventitious Total

\section{4}

4

$7 *$

6

3

5

3

4

3

4
13
Number of Observing Responses

$1 *$
$2 *$
0
$8 *$
$9 *$
$10^{*}$
$7 *$
$13 *$
11
13

data are mute, but of several possibilities, contiguity with some other response seems the most likely candidate. It would seem that Maier's notion of direction (Maier, 1930), as well as Saugstad's concept of availability of function (Saugstad, 1958), demand occurrence of solution upon initial contact with the functionally fixed object. In no case did this occur. The contiguity hypothesis, if not directly supported by, is at least compatible with the data obtained. Further work investigating the relation between rate of observing responses and solution time should shed light upon this issue. Direct tests of the contiguity hypothesis applied to functional fixedness must await techniques for independent manipulation of observing responses from other behavioral chains.

\section{References}

COFER, C. N. Reasoning as an associative process. II. The role of verbal responses in problem solving. J.gen. Psychol., 1957, 57, 55-68.

*Denotes category of contact immediately prior to solution.

The relation between observing behavior and problem solving is given by the data presented in Table 2. Seven of eight Ss solving used the box immediately after touching it while reaching for tacks. These Ss were all in the process of tacking the candle to the wall and were repeatedly reaching into the box for more tacks. When asked, "When did you think of using the box?" six of these seven Ss reported that the idea occurred to them when they happened to touch the box. The seventh $\mathrm{S}$ could not say. The remaining $\mathrm{S}$ did not attempt to use tacks but kept exploring until, as he put it, "I touched the box and got the idea to use it."

With respect to the questions posed, the data are unequivocal. Problem solution does not occur upon first contact with the box, but does occur at the time of a contact. This implies that the observing response is a necessary but not sufficient condition for problem solution. The question arises, under what conditions will an observing response lead to solution? On this point the
DUNCKER, K. On problem-solving. Psychol. Monogr., 1945, 58, No. 5 (Whole No. 270).

GLUCKSBERG, S. The influence of strength of drive on functional fixedness and perceptual recognition. J. exp. Psychol., 1962, 63, 36-41. Perception and mediation in concept learning. J. exp. Psychol., 1961, 61, 186-191.

KENDLER, H. H., \& KENDLER, T.S. Vertical and horizontal processes in problem solving. Psychol.Rev., $1962,69,1-16$.

MAIER, N. R. F. Reasoning in humans. I. On direction. J. comp. Psychol., 1930, 10, 115-143.

SAUGSTAD, P. Availability of functions. A discussion of some theoretical aspects. Acta Psychol., 1958, 13, 384-400.

UNDERWOOD, B. J. An orientation for research on thinking. Psychol. Rev., 1952, 59, 209-220.

\section{Note}

1. This research was supported by Grant MH 08657-01 from the United States Public Health Service.
KENDLER, H. H., GLUCKSBERG, S., \& KESTON, R. 